\title{
Configurações
}

Revista de sociologia

\section{Catarina Frois (org.), A Sociedade Vigilante- Ensaios sobre identificação, vigilância e privacidade}

Rui Vieira Cruz

\section{(2) OpenEdition}

Edição electrónica

URL: http://journals.openedition.org/configuracoes/880

DOI: $10.4000 /$ configuracoes.880

ISSN: 2182-7419

Editora

Centro de Investigação em Ciências Sociais

Edição impressa

Data de publição: 5 fevereiro 2011

Paginação: 185-189

ISSN: 1646-5075

\section{Refêrencia eletrónica}

Rui Vieira Cruz, "Catarina Frois (org.), A Sociedade Vigilante- Ensaios sobre identificação, vigilância e privacidade », Configurações [Online], 8| 2011, posto online no dia 21 fevereiro 2013, consultado o 22 setembro 2020. URL : http://journals.openedition.org/configuracoes/880 ; DOI : https://doi.org/ $10.4000 /$ configuracoes. 880

Este documento foi criado de forma automática no dia 22 setembro 2020. 


\title{
Catarina Frois (org.), A Sociedade Vigilante- Ensaios sobre identificação, vigilância e privacidade
}

\author{
Rui Vieira Cruz
}

\section{REFERÊNCIA}

Catarina Frois (org.), A Sociedade Vigilante- Ensaios sobre identificação, vigilância e privacidade,2008, Imprensa de Ciências Sociais

1 De que forma as tecnologias permitem a identificação dos indivíduos?Como possibilitam o controlo e a vigilância? Como é a privacidade afectada? São estes os desafios sociológicos e antropológicos presentes no livro A Sociedade Vigilante: Ensaios sobre identificação, vigilância e privacidade, organizado por Catarina Frois, que junta um conjunto de ensaios de investigadores nacionais e internacionais. A obra problematiza a implementação e a legitimação dos mais variados mecanismos de controlo nas sociedades contemporâneas, tais como as câmaras de vigilância (CCTV), o policiamento, os cartões de identificação, as políticas de protecção da privacidade individual, a recolha e utilização de dados (estatísticos e genéticos) pessoais, quer com finalidades governamentais, quer comerciais.

Dividida conceptualmente em três partes - i) Identificação; ii) Vigilância; iii) Privacidade -, a obra reflecte acerca dos moldes como a identificação do indivíduo é executada, a forma como esta informação é traduzida num conjunto de dados que são passíveis de ser contabilizados e categorizados. Tal possibilita o controlo e a vigilância, de forma a prever tendências, comportamentos, transformando aparentes perfis (e.g., de consumidor, genéticos, internet) individuais em dados colectivos agregados e categorizados. No momento em que os actos de identificar e vigiar se fundem é levantada a questão da privacidade, com as implicações éticas e morais que acarretam, tais como estigmatização, discriminação e categorização social. 
3 O primeiro capítulo da Parte I, "Identificação", da autoria de José Luís Garcia, demonstra como o uso do corpo combinado com a evolução das técnicas antropométricas e dactilométricas permitem a identificação do indivíduo, mas sobretudo a sua transformação numa série de indicadores que possibilitam não só uma contabilidade, mas também uma categorização burocrática. Desde a sua descoberta no século XIX que as impressões digitais começaram a ser utilizadas no reconhecimento de criminosos e de indivíduos com comportamentos desviantes. Segundo o autor, a evolução da biometria - enquanto forma de leitura das variadas partes do corpo extravasa a leitura das impressões digitais, passando para a análise da íris dos olhos ou da palma da mão, constituindo um conjunto de mecanismos que estão progressivamente a permitir o reconhecimento e a identificação dos cidadãos. Os efeitos perversos desta técnica, de que no passado foi exemplo a eugenia resultante de interpretações da perspectiva evolucionista de Darwin, fomentam o aperfeiçoamento de conjuntos de indivíduos, mas também promovem a identificação e eliminação de determinados grupos ou colectivos. Actualmente, de entre potenciais avanços na medicina, o ADN mostra também esta possibilidade (de controlo e vigilância) na (pré) identificação de indivíduos que fogem à norma numa sociedade tida como sendo liberal e democrática em relação ao passado.

4 Manuela Ivone Cunha, no segundo capítulo, discute a dimensão penal da sociedade disciplinar (na esteira de Foucault) no contexto da sociedade de controlo. Assim percepciona-se que as prisões não podem presentemente ser entendidas somente através do ângulo da repressão. O sistema punitivo moderno pretendeu disciplinar através de um conjunto de técnicas de vigilância, diagnóstico e transformação dos indivíduos. Tal permitia não só aplicar a punição aos indivíduos mas organizar e sistematizar a correcção destes intervindo nos seus comportamentos pessoais. A evolução para um sistema penal pós-moderno, contudo, não visa tratar, corrigir ou conhecer os indivíduos, nem sequer transformá-los, dado tratar-se de um processo dispendioso e de elevada dificuldade. Desta forma, a nova vigilância tecnológica pretende (quase exclusivamente) maximizar a segurança não tendo o objectivo de correcção comportamental.

5 A parte 2 - "Vigilância" - abre com o ensaio de Gary T. Marx, que analisa a questão da colaboração e cedência "voluntária" dos dados pessoais dos cidadãos. Este acto de "voluntariedade involuntária" pode obrigar tanto a uma aceitação das regras impostas, quanto, em caso de rejeição, à recusa dos serviços prestados ou ao abandono do local em que a vigilância é realizada. A título de exemplo: a videovigilância apresenta-se como uma actividade (aparentemente) pouco invasiva para o indivíduo em que, a troco de uma noção de bem comum (ou mesmo de uma recompensa), este é manipulado a cooperar com as autoridades ou com empresas, cedendo a sua informação pessoal para fins que não os inicialmente previstos. Na sequência do exemplo supramencionado, o autor demonstra a importância de um código jurídico-normativo que efectivamente proteja os visados das formas algo difusas, enganadoras e disfarçadas de identificação e vigilância.

6 O quarto capítulo, da autoria de Catarina Frois, dá especial atenção à proliferação de variadas bases de dados de que são exemplos a criação e implementação do cartão do cidadão, as bases de dados de ADN (com propósitos civis e criminais) e as câmaras de vigilância no espaço público enquanto estratégia governamental que visa a melhoria dos sistemas burocráticos e administrativos com o intuito de tornar Portugal um país 
moderno. Esta questão identitária de Portugal - constituir-se como um país "moderno" - assume, portanto, central protagonismo: ao invés de países que justificam a existência de cartões de identidade ou da videovigilância através da promoção da guerra ao terror, em Portugal, que não está em directo conflito armado com nenhum outro país, a legitimação é efectuada pela utilização da arma modernizadora que é a tecnologia, a fim de evitar o atraso, a mediocridade, a tacanhez e a resignação. A estratégia do Simplex/Plano Tecnológico (implementado pelo Partido Socialista durante os XVII e XVIII Governos Constitucionais - entre 2005 e 2011) e o recurso a expressões como "choque tecnológico" comportam elementos dinâmicos de transmissão da ideologia de progresso e de "ser moderno" aos cidadãos.

7 David Lyon, no quinto capítulo do livro, centra a análise numa prática já estabelecida em Portugal: a introdução de dados biométricos nos cartões de identificação dos cidadãos. Embora em Portugal o bilhete de identidade já exista desde o início do século XX, países como o Canadá, Reino Unido e Estados Unidos da América deparam-se presentemente com a possibilidade de criação de cartões de identificação contendo dados biométricos. 0 autor sustenta que os cartões de identificação, que serviam, no passado, propósitos quase exclusivamente nacionais, permitem agora um reconhecimento e validação internacionais que poderão promover a categorização social, estigmatização e discriminação. Argumentos assentes na segurança, no controlo de ameaças terroristas e na travagem da imigração ilegal servem a legitimação dos cartões de identidade em discursos nos quais a preocupação com a segurança nacional prevalece sobre a segurança pessoal, liberdades civis e interesses privados. Os discursos criados para a promoção de uma situação de excepção - a guerra ao terror - estão a criar a nova "normalidade" nas políticas de vigilância, eclipsando uma variedade de questões éticas e políticas.

8 Nesta sequência, Helena Machado e Susana Silva, no sexto capítulo, debatem a relação/ ligação da biotecnologia com as bases de dados genéticos com os dispositivos de vigilância. A articulação de conceitos como biocidadania, Estado e voluntariedade permite uma problematização da fiabilidade do ADN enquanto arma de prevenção e combate ao crime. A objectividade do perfil de ADN serve para justificar e legitimar a aç̧ão do Estado, da ciência e do direito, fundindo-se com a veiculação da ideia de que o cidadão cumpridor da lei nada tem a temer com a utilização da base de dados de perfis de ADN. Contudo, os erros que ocorrem nos processos de recolha, armazenamento, transporte, manuseamento e análise das amostras biológicas não estão previstos na lei e a resolução dessas questões é remetida para a esfera das competências das forças policiais e dos cientistas forenses.

9 No sétimo capítulo, Chiara Fonio investiga o modo como o corpo é utilizado enquanto fonte de informação para identificação e os impactos do factor humano nas câmaras de vigilância CCTV. A existência de cerca de seiscentas câmaras de vigilância na cidade de Milão (de que se excluem as mais de mil câmaras presentes no sistema de transportes) comporta novas acções e competências da polícia local. Chiara Fonio demonstrou como o olhar do operador das câmaras CCTV se revelou selectivo, discriminatório e voyeurista. A formulação de juízos de valor a priori por parte dos videovigilantes conduziu à observação padronizada de indivíduos de determinada faixa etária, sexo, fenótipo e etnia. Os videovigilantes recorriam, assim, a processos de construção social do desvio como forma de justificação do seu alvo de vigia. 
10 Susana Durão centra o oitavo capítulo do livro na entidade com autoridade para vigiar: a polícia. As forças policiais, pela implementação tecnológica e modernização nos seus serviços, têm conhecido diversas modificações na prestação das suas tarefas. Pelo estudo de várias esquadras na cidade de Lisboa, constatou-se a existência de uma maior aposta estratégica na publicitação dos resultados recorrendo a estatísticas mediáticas do que no reforço da capacidade dos agentes policiais junto dos cidadãos. As práticas que acompanham a criação dos polícias-gestores e dos polícias-de-rua criam dinâmicas de vigilância e de controlo assentes ora em estratégias administrativas e jurídicas estatais, ora no conjunto de experiências e saberes (mas também nas pressões) que acompanham os agentes policiais. Contudo, a ênfase dada ao "bom" polícia - aquele que é proactivo, capaz de criar factos e eventos políticos - tem secundarizado o papel dos agentes de patrulha.

11 Na última secção do livro (Parte 3) - "Privacidade" - o ensaio de Ian Kerr e Valerie Steeves foca as questões de vigilância online pelo prisma da invasão da privacidade pessoal com finalidades unicamente comerciais, junto de crianças e adolescentes. $\mathrm{O}$ poder da Internet como um instrumento de vigilância global coloca novas questões e problemas quanto à regulação da privacidade no espaço virtual, afectando todos os grupos sociais independentemente da idade ou nacionalidade. Analisando diversos sítios de jogos interactivos, os autores verificaram que a recolha e armazenamento de dados pessoais conduz ao processamento de perfis de identidade, orientando as crianças e os jovens para um conjunto específico de produtos com base na informação que estes transmitem. Através de inúmeros casos, os autores exemplificam e categorizam a forma como empresas com objectivos comerciais lidam com a sua audiência online. $O$ controlo assume, assim, uma nova faceta: quem está a interagir com as crianças? Quais os seus objectivos e de que forma obtêm os dados pessoais? Como podem os pais, educadores, família controlar a informação que estes divulgam online?

O último capítulo do livro, da autoria de Charles Raab, coloca outra questão central: perante o crescimento da utilização das tecnologias de vigilância, será que a regulação da privacidade tem acompanhado a evolução tecnológica verificada? Os Estados, através de políticas de regulação da privacidade, criam sistemas regulatórios assentes nas suas próprias leis nacionais baseadas nas especificidades e particularidades identitárias. Ao invés, a abrangência da vigilância extravasa as esferas local e nacional, gerando choques de legislação entre vários países. As práticas de regulação parecem, por isso, fragmentadas, pouco coordenadas e algo inadequadas, uma vez que a regulação não tem acompanhado a evolução das tecnologias. Charles Raab sugere uma maior divulgação dos direitos, das opções existentes para os vários actores e agentes tais como Estado, empresas, cidadãos, entre outros, e formas de debate alargado acerca dos prós e contras da divulgação da informação pessoal.

13 A multiplicidade de temas tratados em A Sociedade Vigilante: Ensaios sobre identificação, vigilância e privacidade, gera uma profunda reflexão sobre distintas aplicações empíricas de diversas tecnologias, de onde só estranhei a ausência do tratamento da temática da convergência tecnológica, uma vez que a maioria dos artigos aborda tecnologias convergentes em que a transformação ocorrida numa das áreas promove uma quase imediata alteração nas outras. $\mathrm{O}$ antagonismo registado na obra entre tecnologias e órgãos de regulação tende a obscurecer os conflitos existentes na evolução técnica das diversas tecnologias que consequentemente comportarão efeitos nas normas de regulação. No livro, são englobados os domínios da ciência e tecnologia, 
identidade, cultura, crime, trabalho e profissões, educação, o que o torna numa obra plural, mas nunca dispersa.

AUTORES

RUI VIEIRA CRUZ

Centro de Investigação em Ciências Sociais, rmvcruz@gmail.com 